\title{
Incidência de Fusarium spp. em milho: da planta ao grão
}

\author{
Incidence of Fusarium spp. in corn: from plant to grain \\ Incidencia de Fusarium spp. en el maíz: de la planta al grano
}

\section{Resumo}

É difícil de ser estabelecido o momento em que os fungos fitopatogênicos afetam os grãos quando ainda no campo, sendo Fusarium um dos principais fungos da cultura do milho que causa perda de produtividade e qualidade dos grãos produzidos. Assim objetivou-se com este estudo quantificar a incidência de Fusarium spp. na cultura do milho em função dos estádios fenológicos, em diferentes híbridos e épocas de plantio. Avaliou-se a indicidência do fungo nas folhas, pendões e espigas, pelo método de isolamento indireto de fungos fitopatogênicos. As coletas dos materiais foram realizadas nos estádios V7, VT, R1, R3, R4, R6 e pré-colheita, nas épocas de plantio Dezembro à Março ( $1^{\mathrm{a}}$ safra) e Março à Junho ( $2^{\mathrm{a}}$ safra). Os híbridos avaliados na $1^{\mathrm{a}}$ safra foram ADV 9275 PRO e SEMPRE $20 \mathrm{~A} 30$ e na $2^{\mathrm{a}}$ safra, RB9110PRO2, 2B512PW, 2B633PW e 2A401PW. Os híbridos apresentaram a mesma tendência de incidência de Fusarium spp. nas folhas e pendões em ambas as safras. Os estádios reprodutivos demostraram elevada incidência de Fusarium spp. em todas as partes da planta avaliadas, sendo que nos estádios R6 e pré-colheita observou-se as maiores incidências fúngicas, independente do híbrido e época de plantio. Os híbridos SEMPRE 20A30, 2A401 PW e 2 B512 PW obtiveram maior incidência de Fusarium spp., enquanto que o material RB9110 PRO2 apresentou maior resistência ao fungo. $\mathrm{Na} 1^{\mathrm{a}}$ safra os híbridos apresentaram maior incidência do fitopatógeno na espiga, enquanto que na $2^{\mathrm{a}}$ safra houve maior incidência na folha e no pendão.

Palavras-chave: Estádios fenológicos; Sanidade; Zea mays.

\begin{abstract}
It is difficult to establish the moment when phytopathogenic fungi affect the grains while still in the field, being Fusarium one of the main fungi in the corn crop that causes loss of productivity and quality of the grains produced. Thus, the aim of this study was to quantify the incidence of Fusarium spp. in corn crop as a function of phenological stages, in different hybrids and planting times. The incidence of the fungus on leaves, tassels and ears was evaluated by the indirect isolation method of phytopathogenic fungi. Material collections were carried out at stages V7, VT, R1, R3, R4, R6 and pre-harvest, in the planting times December to March (1st harvest) and March to June (2nd harvest). The hybrids evaluated in the 1st crop were ADV 9275 PRO and ALWAYS 20A30 and in the 2nd crop, RB9110PRO2, 2B512PW, 2B633PW and 2A401PW. The hybrids showed the same incidence trend of Fusarium spp. in leaves and tassels in both seasons. The reproductive stages showed a high incidence of Fusarium spp. in all parts of the plant evaluated, and in the R6 and pre-harvest stages the highest fungal incidence was observed, regardless of the hybrid and planting time. The hybrids ALWAYS 20A30, 2A401 PW and 2B512 PW had a higher incidence of Fusarium spp., while the material RB9110 PRO2 showed greater resistance to the fungus. In the 1st crop, the hybrids showed a higher incidence of the phytopathogen in the ear, while in the 2nd crop there was a higher incidence in the leaf and tassel.
\end{abstract}

Keywords: Phenological stages; Sanity; Zea mays. 


\section{Resumen}

Es difícil establecer el momento en que los hongos fitopatógenos afectan los granos aún en el campo, siendo Fusarium uno de los principales hongos en el cultivo del maíz que ocasiona pérdida de productividad y calidad de los granos producidos. Así, el objetivo de este estudio fue cuantificar la incidencia de Fusarium spp. en el cultivo del maíz en función de las etapas fenológicas, en diferentes híbridos y épocas de siembra. La incidencia del hongo en hojas, borlas y mazorcas se evaluó mediante el método de aislamiento indirecto de hongos fitopatógenos. Las recolecciones de material se realizaron en las etapas V7, VT, R1, R3, R4, R6 y precosecha, en los tiempos de siembra diciembre a marzo ( $1^{\mathrm{a}}$ cosecha) y marzo a junio ( $2^{\mathrm{a}}$ cosecha). Los híbridos evaluados en la $1^{\mathrm{a}}$ cosecha fueron ADV 9275 PRO y SIEMPRE 20A30 y en la $2^{\mathrm{a}}$ cosecha, RB9110PRO2, 2B512PW, 2B633PW y 2A401PW. Los híbridos mostraron la misma tendencia de incidencia de Fusarium spp. en hojas y borlas en ambas estaciones. Los estadios reproductivos mostraron una alta incidencia de Fusarium spp. en todas las partes de la planta evaluada, y en las etapas R6 y precosecha se observó la mayor incidencia de hongos, independientemente del híbrido y época de siembra. Los híbridos SIEMPRE 20A30, 2A401 PW y 2B512 PW tuvieron mayor incidencia de Fusarium spp., Mientras que el material RB9110 PRO2 mostró mayor resistencia al hongo. En la $1^{\text {a }}$ cosecha, los híbridos mostraron una mayor incidencia del fitopatógeno en la mazorca, mientras que en la $2^{a}$ cosecha hubo una mayor incidencia en la hoja y la espiga.

Palabras clave: Etapas fenológicas; Cordura; Zea mays.

\section{Introdução}

Dentre os estados brasileiros, o Mato Grosso se destaca como maior produtor nacional de grãos, principalmente milho e soja, sendo a microrregião Médio-Norte a que mais produz. Conforme dados levantados pela CONAB (2021) para a safra 2020/21 a produção total de milho no país foi de 85,7 milhões de toneladas, sendo o Mato Grosso responsável por 33,2 milhões de toneladas. Todavia, mesmo com os avanços na produção do milho no país, a contaminação por fungos, principalmente por Fusarium spp., tem sido um problema tanto no campo, causando perdas na produtividade em razão de podridão no colmo (Costa et al., 2019) e na espiga (Gabriel et al., 2018; Munhoz et al., 2015), com a formação de grãos ardidos, quanto após a colheita, durante o beneficiamento, armazenamento e transporte, resultando em grãos mofados ou embolorados (Pinto, 2005), comprometendo a qualidade dos grãos.

Fatores como, a expansão do plantio para duas safras, a intensificação do cultivo em áreas irrigadas, variedades não recomendadas para determinadas regiões, ampla utilização de defensivos, elevada população de plantas e atraso na colheita podem explicar a crescente incidência fúngica e o surgimento de várias doenças associadas a produção de compostos tóxicos, as micotoxinas (Juliatti, 2007). Essa contaminação por micotoxinas pode fazer com que grãos se tornem impróprios para o consumo humano e animal, resultando em grandes perdas econômicas (Bento et al., 2012). Além disso, o aumento da incidência de Fusarium spp. nos grãos de milho pode ser indicativo de susceptibilidade dos híbridos disponíveis no mercado (Prestes et al., 2019).

O Fusarium spp. é considerado um fungo de campo, no qual invade os grãos e as sementes durante o amadurecimento, pois as condições de temperatura e umidade relativa do ar são mais elevadas, acima de $30{ }^{\circ} \mathrm{C}$ e $90 \%$, respectivamente, e altos teores de água nos grãos, entre 20 e $21 \%$ (b.u.), favorecendo o seu desenvolvimento (Márcia \& Lázzari, 1998). Esse fungo pode sobreviver no solo por meio de estruturas de resistência e, ainda, em estruturas internas das sementes, como o embrião (Costa et al., 2003). Além do mais, o Fusarium spp. tem a capacidade de transmitir-se para outras partes da planta e até mesmo nas espigas de forma sistêmica a partir das sementes (Wilke et al., 2007).

Com isso, a grande dúvida quanto ao manejo ideal é com relação ao momento em que ocorre a infecção dos grãos por fungos fitopatogênicos. Identificando esse momento seria um caminho para a realização de um controle mais preciso da contaminação. Levando em conta os riscos à saúde humana, ocasionada pela ingestão direta ou indireta de micotoxinas originárias da incidência fúngica, devido à falta de informações sobre a época mais crítica da infecção, objetivou-se com o este trabalho quantificar a incidência de Fusarium spp. na cultura do milho em função dos estádios fenológicos, em diferentes híbridos e épocas de plantio. 


\section{Metodologia}

O cultivo do milho foi conduzido em área comercial na região Norte de Mato Grosso, no município de Sinop, durante a $1^{\mathrm{a}}$ e $2^{\mathrm{a}}$ safras do ano agrícola de 2016/2017. No cultivo em $1^{\mathrm{a}}$ safra, a semeadura foi realizada em $1^{\circ}$ de dezembro de 2016 e a colheita em 06 de março de 2017, enquanto a $2^{\mathrm{a}}$ safra iniciou em 03 de março de 2017 e a colheita realizada em 07 de junho de 2017.

A área do experimento localiza-se nas coordenadas $11^{\circ} 54^{\prime} 14^{\prime \prime} \mathrm{S}$ e $55^{\circ} 29^{\prime} 29^{\prime \prime} \mathrm{W}$, na qual o tipo de solo predominante é o latossolo vermelho-amarelo, com areia quartzosa. O clima da região de acordo com Köppen e Geiger (1936) é do tipo (Aw) definido como tropical chuvoso (quente-úmido) com duas estações bem definidas, uma seca no período de inverno e outra chuvosa no período de verão. Os meses de maior pluviosidade são janeiro, fevereiro e março, e os de menor pluviosidade são junho, julho e agosto. A precipitação média anual é entre 1.800 e 1.900 milímetros e as temperaturas médias mensais oscilam entre $23,0^{\circ} \mathrm{C}$ e $25,8^{\circ} \mathrm{C}$, com valor médio anual de $24,7^{\circ} \mathrm{C}$ (Souza et al., 2013).

$\mathrm{Na} 1^{a}$ safra foram semeados dois híbridos de milho, distribuídos em dois talhões, um para cada material, com dimensões de $50 \mathrm{~m}$ de largura por $150 \mathrm{~m}$ de comprimento, espaçamento entre linhas de $0,80 \mathrm{~m}$ e 6 sementes por metro. $\mathrm{Na} 2^{\mathrm{a}}$ safra quatro híbridos de milho foram utilizados e dispostos em talhões com $7 \mathrm{~m}$ de largura por $150 \mathrm{~m}$ de comprimento, com espaçamentos e quantidade de sementes por metro igual a $1^{\mathrm{a}}$ safra. $\mathrm{O}$ tratamento de sementes e os tratos culturais foram realizados de acordo com as indicações técnicas para a cultura do milho, promovendo a proteção de plantas contra pragas e doenças, conforme tratamento adotado pelos produtores na região, em ambas as safras.

Na $1^{\mathrm{a}}$ safra foram utilizados os híbridos ADV9275 PRO e SEMPRE 20A30, ao passo que na $2^{\mathrm{a}}$ safra foram os híbridos RB9110 PRO2, 2B512PW, 2B633PW e 2A401PW. Na Tabela 1 são descritas as características específicas de cada híbrido avaliado no experimento.

Tabela 1. Características dos híbridos avaliados.

\begin{tabular}{|c|c|c|}
\hline Híbridos & Regiões recomendadas & Características \\
\hline ADV 9275 PRO & $\begin{array}{l}1^{a} \text { safra no Sul do país e } 2^{a} \text { safra no } \\
\text { Norte do Centro Oeste. }\end{array}$ & $\begin{array}{l}\text { Precocidade, potencial produtivo e, alta tolerância a } \\
\text { Phaoesphaeria maydis e Cercospora zea maydis. }\end{array}$ \\
\hline SEMPRE 20A30 & $\begin{array}{l}\text { Regiões Nordeste, Centro-Oeste, } \\
\text { Sudeste e Sul. }\end{array}$ & $\begin{array}{l}\text { Precocidade, sanidade foliar e resistência moderada } \\
\text { a podridão na espiga. }\end{array}$ \\
\hline RB 9110 PRO 2 & $\begin{array}{l}\text { Maranhão, Bahia, Piauí, Minas } \\
\text { Gerais, Roraima e Sul do país. }\end{array}$ & $\begin{array}{l}\text { Superprecocidade, potencial produtivo e ótima } \\
\text { sanidade de colmo e raízes. }\end{array}$ \\
\hline 2B512PW & $\begin{array}{l}\text { Regiões Nordeste, Centro-Oeste, } \\
\text { Sudeste e Sul. }\end{array}$ & $\begin{array}{l}\text { Precocidade, resistência física da raiz alta, sanidade } \\
\text { geral e sanidade de grãos. }\end{array}$ \\
\hline 2B633PW & $\begin{array}{l}\text { Regiões Nordeste, Centro-Oeste, } \\
\text { Sudeste e Sul. }\end{array}$ & $\begin{array}{l}\text { Precocidade, potencial produtivo, sanidade foliar e } \\
\text { resistente a doenças foliares. }\end{array}$ \\
\hline 2A401PW & $\begin{array}{l}\text { Regiões Nordeste, Centro-Oeste, } \\
\text { Sudeste e Sul. }\end{array}$ & $\begin{array}{l}\text { Superprecocidade, potencial produtivo e sanidade } \\
\text { foliar e do colmo. }\end{array}$ \\
\hline
\end{tabular}

Fonte: ItagiAgro (2021), Sementes (2021), KWS (2021), Forseed (2021a), Forseed (2021b) e Brevant (2021).

Na Figura 1 são descritos os estádios fenológicos da cultura do milho avaliados quanto a incidência de Fusarium spp. Visto a necessidade de identificação do fungo na planta e, principalmente, o momento em que ocorre a infecção, visando melhor controle durante o manejo da cultura, foram avaliadas variações de incidência na folha, no pendão e na espiga da planta nos respectivos estádios fenológicos. Assim, para a folha os estádios avaliados foram entre V7 até pré-colheita, para o pendão iniciou em VT, ou seja, a fase em que ocorre o surgimento do pendão, até a pré-colheita, e para a espiga a partir do estádio reprodutivo R1 e terminando na pré-colheita. Todos os dados coletados foram discutidos de forma descritiva (Pereira et al., 2018). 
Figura 1. Estádios fenológicos da cultura do milho, da emergência até maturação fisiológica.

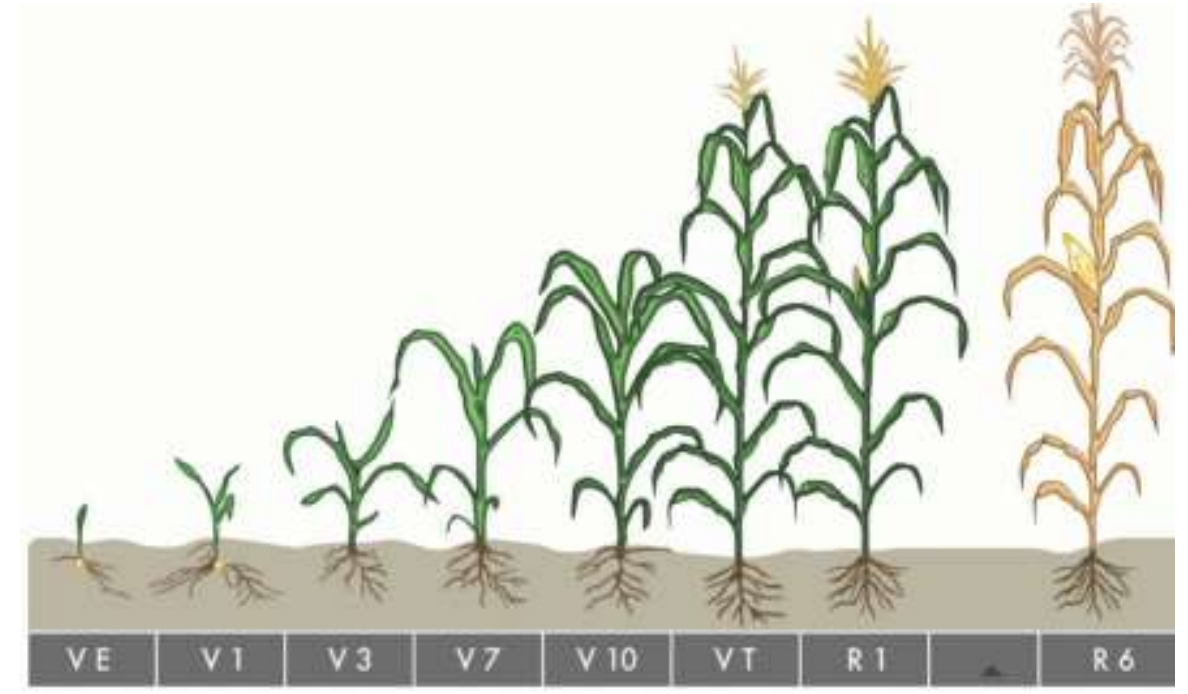

Fonte: Fancelli e Dourado Neto (2000).

Para as avaliações fúngicas, nos estádios fenológicos citados, foram colhidas 4 amostras dos materiais (folha, pendão e espiga) quando presentes. Sendo 4 folhas inteiras, 4 pendões inteiros e 4 espigas, de cada híbrido, em 4 sub parcelas demarcadas nos talhões. As amostras coletadas foram acondicionadas em embalagens de papel kraft, e encaminhadas para o laboratório de Pós-colheita da Universidade Federal de Mato Grosso, campus de Sinop.

Antes da realização das análises, o material foi submetido a pré-secagem em estufa com circulação forçada de ar, à temperatura de $55{ }^{\circ} \mathrm{C}$, sendo que para folhas e pendões por um período de aproximadamente 45 minutos e para a espiga cerca de 1 hora e 25 minutos para redução de teor de água, minimizando assim a deterioração do material até realização das análises. Após a secagem, as amostras foram armazenadas em câmara tipo B.O.D. na temperatura de $3{ }^{\circ}$ C. Na sequência, foram realizados os procedimentos para avaliação da incidência fúngica no material colhido em cada fase da cultura.

O isolamento indireto de fungos fitopatogênicos foi realizado, conforme a metodologia descrita em Regras de Análise para Sementes (Brasil, 2009) e nos Métodos em Fitopatologia (Alfenas \& Mafia, 2007). Essa técnica consiste na transferência para o meio de cultura, de porções infectadas de tecido do hospedeiro, sendo que em muitos casos o patógeno está dentro dos tecidos da planta, sem produzir frutificações na superfície do órgão lesionado.

Para o isolamento de fungos dos tecidos como folhas e pendão, realizou-se isolamento indireto. Para isto realizou-se a lavagem do material infectado com água e detergente, retirando o excesso de água com papel-filtro. Com o auxílio de uma lâmina previamente flambada foram retirados os fragmentos das margens da lesão e transferidos para uma solução de álcool 70\%, onde permaneceram por cerca de 30 segundos. Em seguida, fez-se a transferência dos fragmentos de tecido para a solução desinfetante, hipoclorito de sódio a $1.000 \mathrm{ppm}(0,1 \%)$ de $\mathrm{Cl}_{2}$. Os fragmentos permaneceram imersos na solução, por cerca de 30 segundos, de forma a eliminar os contaminantes superficiais sem afetar o patógeno no interior dos tecidos. Após, com o auxílio de uma pinça flambada, foram removidos fragmentos da solução desinfetante e colocados em água destilada por 30 segundos. O excesso de água foi removido deixando os fragmentos por 45 segundos em papel filtro. Na sequência foram colocados quatro fragmentos por placa de Petri com o meio de cultura BDA (Ágar batata dextrose), e as placas foram então mantidas a $25^{\circ} \mathrm{C}$ em incubadora do tipo B.O.D até o crescimento do fungo. Cerca de 7 dias após incubação, foi realizada a identificação do fungo Fusarium spp. presente na placa com o auxílio de microscópio óptico (AF: 400x).

Para as espigas seguiu-se o mesmo procedimento da análise de folhas e pendões, porém ao invés de fragmentos foi utilizado espigas inteiras. Após a pré-secagem, 4 espigas por amostra foram dispostas em uma bandeja com papel germitest umedecido, em que cada bandeja representa uma coleta. A bandeja foi vedada com papel filme e colocada em câmara úmida, na 
temperatura de $25{ }^{\circ} \mathrm{C}$ por 7 dias. Após este período quantificou-se o número de espigas que continham sinais do fungo Fusarium spp.

Segundo Nirenberg e O’ Donnel (1998) as espécies de Fusarium spp. identificadas no milho, tem como principais características ausência de clamidósporo e a disposição dos microconídios sobre a célula conidiogênica.

Para verificação das condições climáticas foram obtidos dados de temperatura e umidade relativa pelo Instituto Nacional de Meteorologia (INMET, 2021). Estes dados são coletados pela estação automática instalada no município de Sinop, na Gleba Celeste, com latitude de $-12,2^{\circ}$ e longitude de $-55,6^{\circ}$, além de possuir altitude média de $415 \mathrm{~m}$. Os dados de precipitações foram registrados por meio de um pluviógrafo instalado na área de cultivo de milho.

\section{Resultados e Discussão}

A precipitação acumulada durante a $1^{\mathrm{a}}$ safra foi de aproximadamente $1.000 \mathrm{~mm}$ e para a $2^{\mathrm{a}}$ safra foi em torno de 470 mm (Figuras 2 e 3). Segundo Oliveira et al. (2018) a precipitação média necessária por ciclo do milho é de 500 a 800 mm, demonstrando que a quantidade de água ficou próximo do mínimo exigido pela cultura para seu desenvolvimento na $2^{\mathrm{a}}$ safra e com valores bem elevados na $1^{\mathrm{a}}$ safra.

A distribuição das chuvas ao longo do ciclo da cultura de milho apresentou diferenças entre as duas safras estudadas. Durante a $1^{\text {a }}$ safra, a precipitação foi bem distribuída, porém em quantidades diferentes, a exemplo, tem-se precipitação mínima de $3 \mathrm{~mm}$ em 27 de janeiro de 2017 e máxima de 117,5 mm em 16 de dezembro de 2016. Na 2aa safra, por ser um período mais seco na região, choveu o necessário para o desenvolvimento da cultura, porém não ocorreu de forma homogênea, havendo estiagem de até 15 dias no mês de maio, coincidindo com estádio reprodutivo R4, ou seja, quando a espiga de milho apresenta grãos com consistência pastosa. Segundo Mendes et al. (2011), a redução do volume de precipitação durante fase de enchimento do grão (a partir do R2) e no final do ciclo da cultura pode favorecer na menor incidência de fungos patógenos nos grãos.

Figura 2. Precipitação diária e acumulada durante o cultivo de milho na $1^{\mathrm{a}}$ safra.

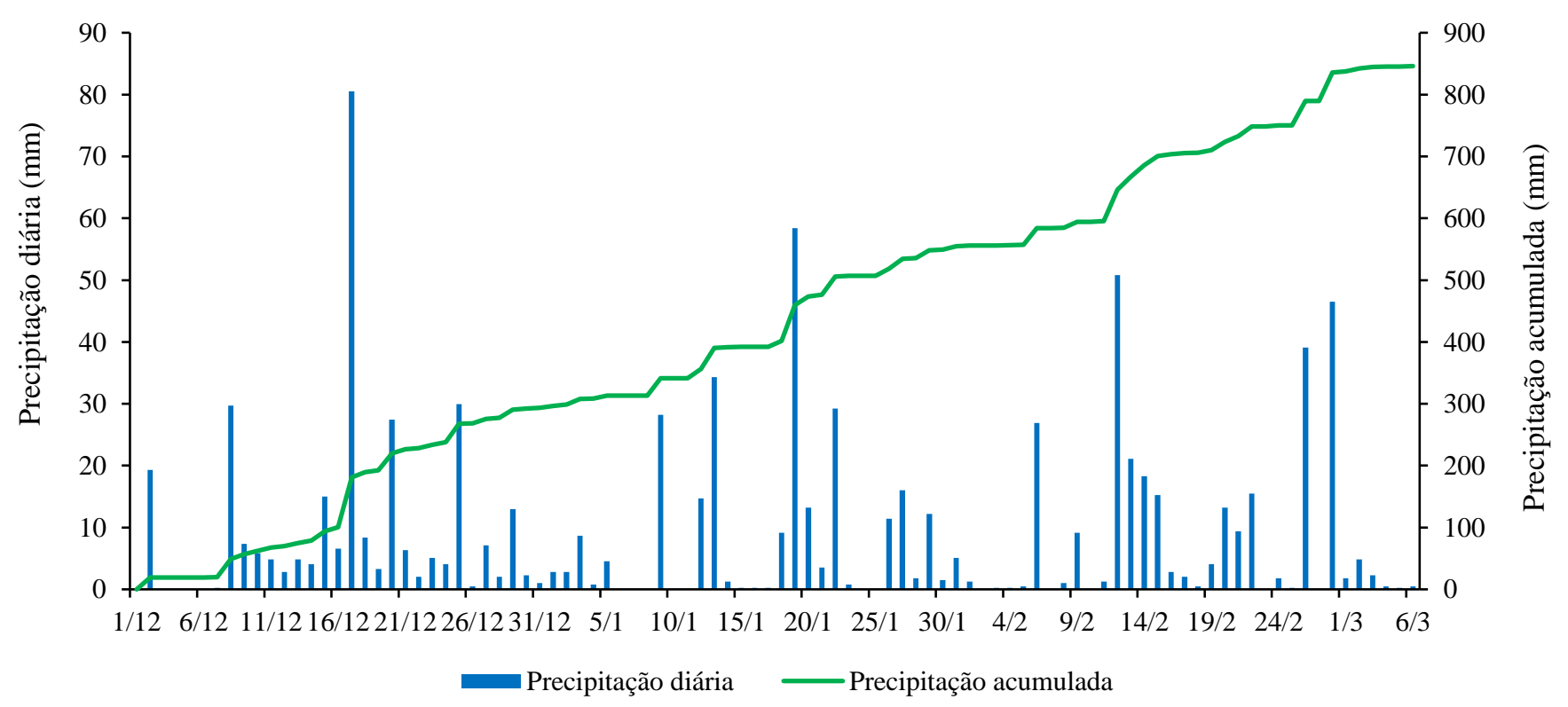

Fonte: Autores. 
Figura 3. Precipitação diária e acumulada durante o cultivo de milho na $2^{\mathrm{a}}$ safra.

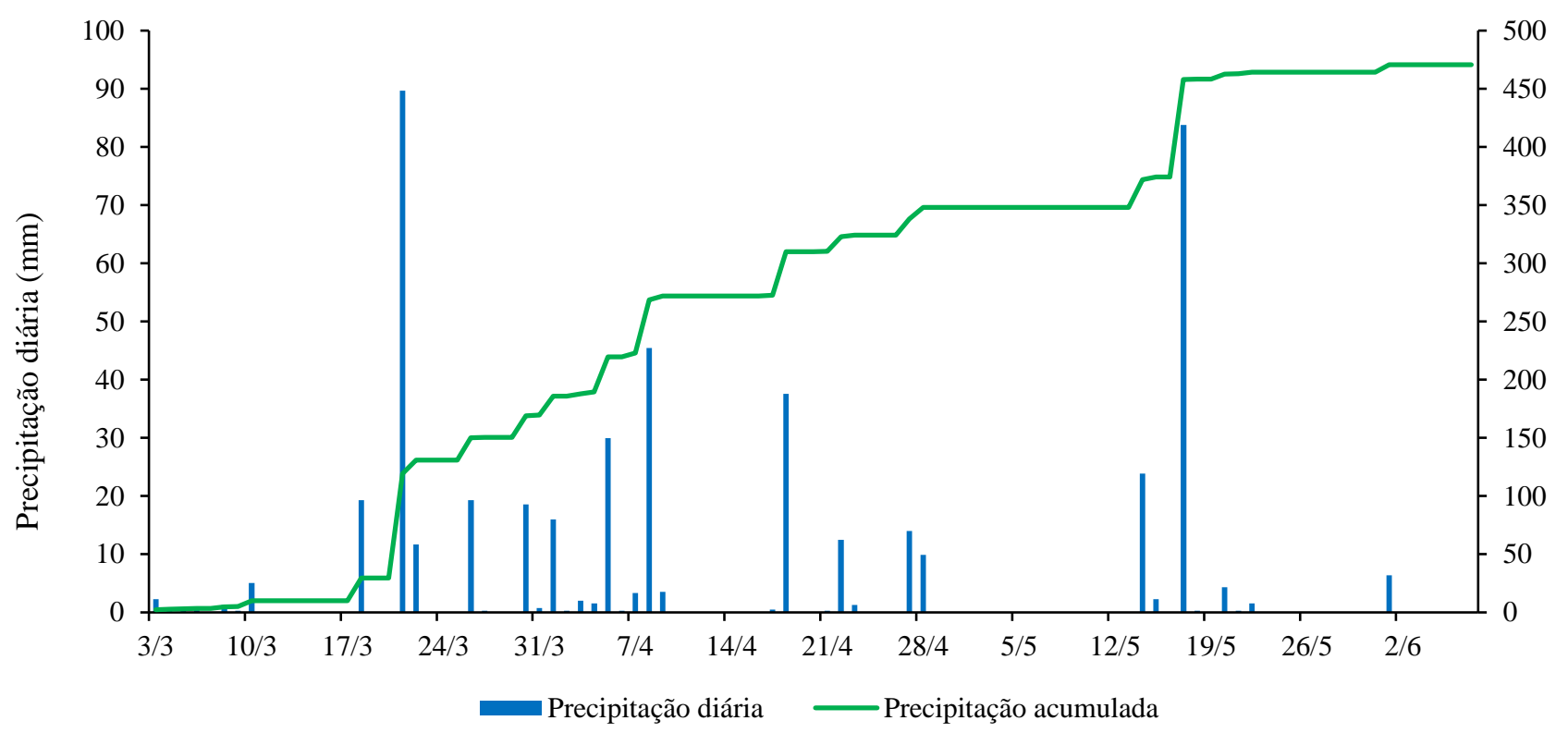

Fonte: Autores.

A variação do menor e maior valor registrado para a temperatura média do ar foi de 22,6 a $28,2{ }^{\circ} \mathrm{C}$ e de 23,6 a $28,9{ }^{\circ} \mathrm{C}$, ao passo que a umidade relativa média do ar variou entre 67,75 a $98,5 \%$ e de 63,75 a $96,75 \%$, respectivamente, para a $1^{\circ}$ e $2^{\circ}$ safra (Figura 4).

Segundo Santin et al. (2000), para o desenvolvimento de Fusarium spp. o microclima ideal deve apresentar temperatura média variando entre 20 a $26^{\circ} \mathrm{C}$, enquanto que Prestes et al. (2019) afirmam que o crescimento desse fungo é favorecido em temperaturas próximas a $30^{\circ} \mathrm{C}$. De acordo com Silva (2008) a umidade relativa do ar para a colonização de fungos nos grãos em campo deve ser elevada, em torno de 90\%. Todavia, no trabalho de Venceslau et al. (2015), os autores observaram a incidência de nove gêneros diferentes de fungos nos grãos de soja, incluindo Fusarium spp., onde a umidade relativa do ar mantinha média de $84 \%$ e com total precipitado de $79 \mathrm{~mm}$. De modo geral, Kimati et al. (1995) relatam que umidade relativa do ar variando de 70 a $90 \%$ e temperaturas em torno de 25 a $30^{\circ} \mathrm{C}$ proporcionam um ambiente favorável para o desenvolvimento de vários gêneros de fungos, como o Fusarium spp.

Os resultados e discussões apresentados indicam que as condições climáticas na região em que foi realizado este estudo, independente da época de plantio, são favoráveis ao desenvolvimento de Fusarium spp. nos grãos de milho. Assim, tem-se a necessidade de identificação do fungo na planta e, principalmente, o momento ideal em que ocorre a infecção, visando melhor controle durante o manejo da cultura e qualidade sanitária do grão. 
Figura 4. Variações médias da temperatura e umidade relativa do ar durante o cultivo de milho na $1^{\mathrm{a}}$ e $2^{\mathrm{a}}$ safra.

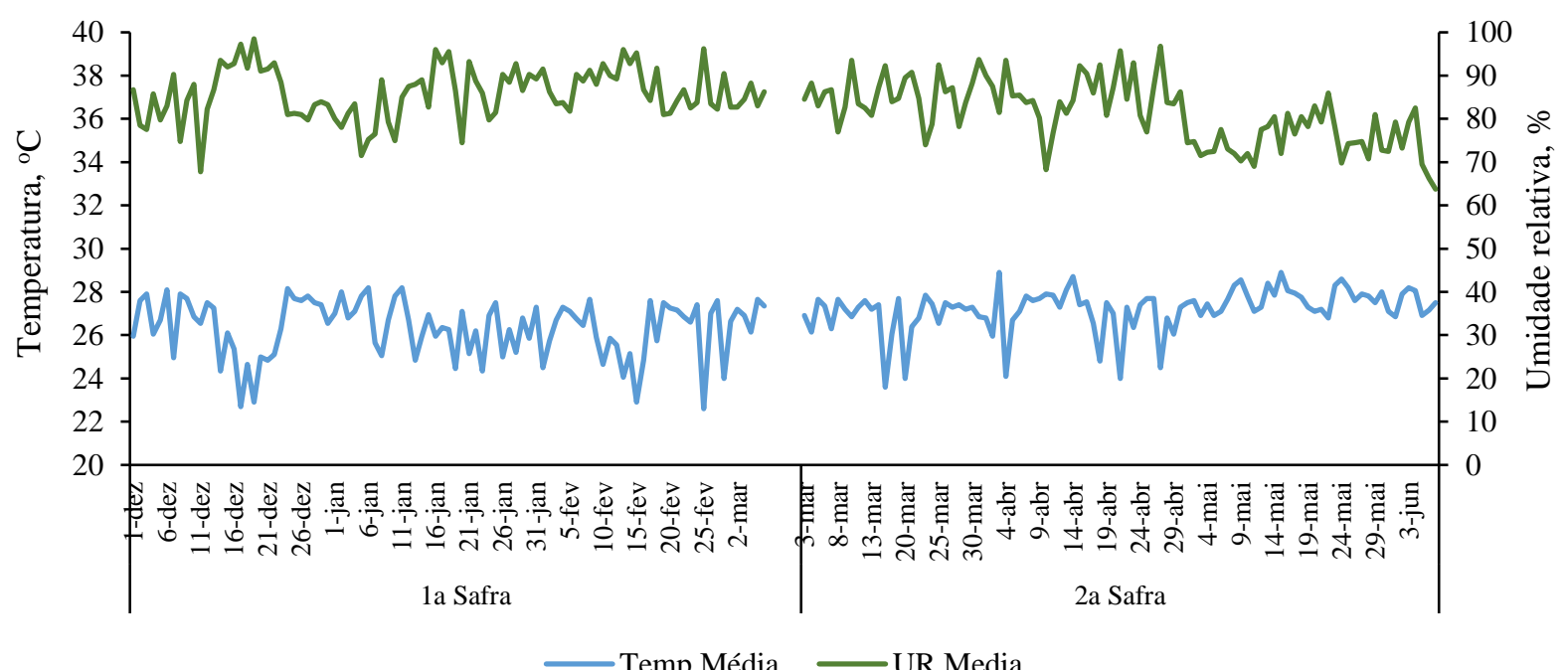

— Temp Média —UR Media

Fonte: Autores.

A presença do Fusarium spp. na folha começou no V7, com exceção dos híbridos RB9110 PRO2, 2A401 PW e 2B512 PW da $2^{\mathrm{a}}$ safra, neste caso, a incidência iniciou no estádio VT (Tabela 2). Nota-se também a tendência de aumento da contaminação fúngica na folha conforme o desenvolvimento da cultura. Além disso, os resultados confirmam maior variação da incidência de Fusarium spp. entre os estádios fenológicos avaliados do que entre os híbridos e a época de plantio. É de grande importância a avaliação das diferentes partes da planta, pois a partir delas o fungo pode-se estabelecer e contaminar futuramente os grãos, podendo levar a reduções no tamanho de espigas e no peso de grãos e espigas como foi observado no trabalho de Costa et al. (2019), comprometendo a produtividade da cultura e qualidade dos grãos.

De fato, outras pesquisas apontam a incidência do Fusarium spp. em diversas partes da planta durante a sua fase vegetativa e reprodutiva. No trabalho de Gaige et al. (2020), os autores avaliaram a colonização das espécies $F$. proliferatum e F. verticillioides na raiz e no colmo da planta de milho no estádio V2, além de analisarem a incidência dos fungos em três distâncias (próximo, médio e longe) entre raiz e a semente, e entre o colmo e a semente. Com isso, os pesquisadores concluíram que a colonização na raiz pelo $F$. proliferatum foi 2,63 vezes maior do que no colmo, enquanto a colonização de $F$. verticillioides foi 2,72 vezes maior na raiz em comparação no colmo. Além disso, as maiores incidências das espécies dos fungos foram localizadas nas regiões mais próximas da semente, tanto para a raiz como para o colmo.

No estudo de Kühn et al. (2020), ao analisarem a incidência de podridão no colmo, ocasionado pelo Fusarium spp., em diferentes híbridos de milho no estádio R2, constataram que para os híbridos DKB290, MG580, AG8544 e AS1633 a incidência da doença foi acima de 70\% com índices que passaram dos 90\% para o híbrido AG8544. Fora isso, esses híbridos também apresentaram espigas contendo grãos com podridão, resultado da transmissão do fungo da planta para o grão.

Os estádios fenológicos finais R6 e pré-colheita alcançaram maior contaminação fúngica, com valores médios de 70,59 e 92,96\% para os híbridos da $1^{\text {a }}$ safra e de 83,59 e 88,28\% para os híbridos da $2^{\text {a }}$ safra, respectivamente. Além disso, observa-se baixa incidência no estádio vegetativo V7 dos híbridos da $2^{\mathrm{a}}$ safra, oscilando entre 0 a 3,12\%. Entre os híbridos avaliados, o híbrido 2B512 PW da $2^{\mathrm{a}}$ safra apresentou a maior incidência de Fusarium spp. na folha, média de 61,60\%, ao passo que no híbrido ADV 9275 PRO da $1^{\text {a }}$ safra observou-se menor média, 52,45\%. Para mais, o híbrido 2B512 PW da $2^{\text {a }}$ safra e entre os estádios R1 e R3 foi a única coleta que apresentou diferença entre os demais resultados, aumentando o seu valor ao invés de reduzir. Por fim, as condições no período da $2^{\text {a }}$ safra favoreceram a maior incidência de Fusarium spp. na folha, aumento $17,6 \%$ em comparação com a $1^{\text {a }}$ safra. 
Quando avaliada a indecência de Fusarium spp. e observada a precipitação diária (Figuras 1 e 2), tem-se que entre as coletas em V7 e VT, e R1 e R3 na $1^{\text {a }}$ safra, e R1 e R3 na 2a safra houve redução da incidência fúngica, coincidindo com períodos de estiagem. O que permite inferir que a atividade fúngica apresentou correlação direta com a disponibilidade de água na cultura. Após esse período e com o retorno das chuvas, houve incremento na incidência a partir do estádio R4 até a pré-colheita para todos os híbridos e em ambas as safras.

Tabela 2. Dados médios observados de incidência (\%) de Fusarium spp. na folha em função do estádio fenológico, em diferentes híbridos e épocas de plantio. Em que: Estádios V7 (sétima folha), VT (pendoamento), R1 (embonecamento), R3 (grão leitoso), R4 (grão pastoso), R6 (maturação fisiológica) e pré-colheita.

\begin{tabular}{|c|c|c|c|c|c|}
\hline \multicolumn{6}{|c|}{ Incidência (\%) de Fusarium spp. na $1^{\text {a }}$ Safra } \\
\hline Estádios & \multicolumn{2}{|c|}{ SEMPRE 20A30 } & \multicolumn{2}{|c|}{ ADV 9275 PRO } & Média geral \\
\hline V7 & \multicolumn{2}{|c|}{23,43} & \multicolumn{2}{|c|}{7,81} & 15,62 \\
\hline VT & \multicolumn{2}{|c|}{9,37} & \multicolumn{2}{|c|}{1,56} & 5,47 \\
\hline $\mathrm{R} 1$ & \multicolumn{2}{|c|}{60,93} & \multicolumn{2}{|c|}{61,04} & 60,99 \\
\hline R3 & \multicolumn{2}{|c|}{37,50} & \multicolumn{2}{|c|}{35,93} & 36,72 \\
\hline R4 & \multicolumn{2}{|c|}{56,25} & \multicolumn{2}{|c|}{37,50} & 46,87 \\
\hline R6 & \multicolumn{2}{|c|}{70,87} & \multicolumn{2}{|c|}{70,31} & 70,59 \\
\hline Pré-Colheita & \multicolumn{2}{|c|}{95,31} & \multicolumn{2}{|c|}{90,62} & 92,96 \\
\hline Média geral & \multicolumn{2}{|c|}{50,52} & \multicolumn{2}{|c|}{43,54} & 47,02 \\
\hline \multicolumn{6}{|c|}{ Incidência (\%) de Fusarium spp. na $2^{\mathrm{a}}$ Safra } \\
\hline Estádios & RB9110 PRO2 & 2A401 PW & 2B512 PW & 2B633 PW & Média geral \\
\hline V7 & 0,00 & 0,00 & 0,00 & 3,12 & 0,78 \\
\hline VT & 40,62 & 46,87 & 45,31 & 28,12 & 40,23 \\
\hline $\mathrm{R} 1$ & 70,31 & 56,25 & 62,50 & 70,31 & 64,84 \\
\hline $\mathrm{R} 3$ & 40,62 & 50,00 & 67,18 & 29,68 & 46,87 \\
\hline $\mathrm{R} 4$ & 71,87 & 76,56 & 82,81 & 68,75 & 75,00 \\
\hline R6 & 81,25 & 87,50 & 84,37 & 81,25 & 83,59 \\
\hline Pré-Colheita & 87,50 & 90,62 & 89,06 & 85,93 & 88,28 \\
\hline Média geral & 56,02 & 58,25 & 61,60 & 52,45 & 57,08 \\
\hline
\end{tabular}

Fonte: Autores.

A incidência do Fusarium spp. no pendão iniciou no estádio de pendoamento (VT) para a maioria dos híbridos e com valores médios superiores a 65,0\% (Tabela 3). A única exceção foi apenas para o híbrido SEMPRE $20 A 30$ da $1^{\text {a }}$ safra, nesse caso, a contaminação fúngica começou no estádio seguinte (R1), com porcentagem de 51,62\%. Assim como na folha, a incidência de Fusarium spp. no pendão foi proporcional aos estádios de desenvolvimento da planta, com grande variação entre as coletas, mas pouca diferença entre os híbridos.

Os estádios fenológicos finais R6 e pré-colheita apresentaram alta porcentagem de contaminação por Fusarium spp., com destaque para o estádio pré-colheita na $1^{\text {a }}$ safra em que todos os híbridos obtiveram $100 \%$ de infestação pelo fungo no pendão. Nota-se também alta incidência do fungo no pendão durante todos os estádios reprodutivos da cultura, sendo superior ao observado na folha. O híbrido $2 \mathrm{~B} 633 \mathrm{PW}$ da $2^{\mathrm{a}}$ safra possuiu a maior média de incidência no pendão (86,46\%) seguindo por RB9110 PRO2 e 2B512 PW, ambos da 2a safra, com valores médios de 84,89 e 83,33\%, respectivamente. A menor incidência no pendão foi registrada para o híbrido SEMPRE 20 A30 da $1^{\text {a }}$ safra, valor médio de 49,49\%. No final do experimento, a $2^{\mathrm{a}}$ safra apresentou maior incidência fúngica no pendão, com média de $83,40 \%$ contra $58,07 \%$ da $1^{\text {a }}$ safra.

Em trabalho semelhante, Scheidt et al. (2019) utilizaram dois isolados do complexo de espécies de Fusarium graminearium 15A (F. graminearium- 15-ADON) e FmNiv (F. meridionale - Nivalenol) na inoculação da planta de arroz (híbrido INOV CL) em três estádios fenológicos e observaram que o estádio de florescimento do arroz foi o mais passível à 
infecção das espécies $F$. graminearum e F. meridionale, quando comparado com os estádios de emborrachamento e espigamento pleno, induzindo maior severidade da doença e incidência de grãos manchados, e a presença dos fungos detectados nos grãos.

Nota-se que a estiagem proporcionou o mesmo efeito na contaminação no pendão, durante o estádio R3 houve redução da indecência de Fusarium spp. e com o retorno da precipitação houve aumento da incidência fúngica para todos os híbridos, independente da safra.

Tabela 3. Dados médios observados de incidência (\%) de Fusarium spp. no pendão em função do estádio fenológico, em diferentes híbridos e épocas de plantio. Em que: Estádios VT (pendoamento), R1 (embonecamento), R3 (grão leitoso), R4 (grão pastoso), R6 (maturação fisiológica) e pré-colheita.

\begin{tabular}{|c|c|c|c|c|c|}
\hline \multicolumn{6}{|c|}{ Incidência (\%) de Fusarium spp. na $1^{\text {a }}$ Safra } \\
\hline Estádios & \multicolumn{2}{|c|}{ SEMPRE 20A30 } & \multicolumn{2}{|c|}{ ADV 9275 PRO } & Média geral \\
\hline VT & \multicolumn{2}{|c|}{0,0} & \multicolumn{2}{|c|}{67,18} & 33,59 \\
\hline $\mathrm{R} 1$ & \multicolumn{2}{|c|}{51,62} & \multicolumn{2}{|c|}{46,87} & 49,25 \\
\hline R3 & \multicolumn{2}{|c|}{40,62} & \multicolumn{2}{|c|}{43,75} & 42,18 \\
\hline $\mathrm{R} 4$ & \multicolumn{2}{|c|}{45,31} & \multicolumn{2}{|c|}{53,12} & 49,21 \\
\hline R6 & \multicolumn{2}{|c|}{59,37} & \multicolumn{2}{|c|}{89,06} & 74,21 \\
\hline Pré-Colheita & \multicolumn{2}{|c|}{100,0} & \multicolumn{2}{|c|}{100,0} & 100,0 \\
\hline Média geral & \multicolumn{2}{|c|}{49,49} & \multicolumn{2}{|c|}{66,66} & 58,07 \\
\hline \multicolumn{6}{|c|}{ Incidência (\%) de Fusarium spp. na $2^{\mathrm{a}}$ Safra } \\
\hline Estádios & RB9110 PRO2 & 2A401 PW & 2B512 PW & 2B633 PW & Média geral \\
\hline VT & 68,75 & 76,56 & 68,75 & 65,62 & 69,92 \\
\hline $\mathrm{R} 1$ & 90,62 & 62,50 & 67,18 & 90,62 & 77,73 \\
\hline R3 & 79,68 & 68,75 & 78,12 & 75,0 & 75,39 \\
\hline $\mathrm{R} 4$ & 85,93 & 82,81 & 89,06 & 93,75 & 87,89 \\
\hline R6 & 84,37 & 92,18 & 96,87 & 93,75 & 91,79 \\
\hline Pré-Colheita & 100,00 & 90,62 & 100,0 & 100,0 & 97,65 \\
\hline Média geral & 84,89 & 78,90 & 83,33 & 86,46 & 83,40 \\
\hline
\end{tabular}

Fonte: Autores.

A incidência do Fusarium spp. na espiga iniciou no estádio R1 para todos os híbridos e com elevadas médias (Tabela 4). Nas duas safras é possível constatar que conforme foram realizadas as coletas, a incidência de Fusarium spp. nas espigas apresentou tendência de aumento, com média geral variando de 50 a $100 \%$ para a $1^{\mathrm{a}}$ safra e de 56,25 a $100 \%$ para a $2^{\mathrm{a}}$ safra. Nota-se que esse resultado na espiga foi semelhante quando comparado com a folha e o pendão, com isso conclui-se uma sequência de aumento na incidência do Fusarium spp. no cultivo do milho, desde a folha até a espiga.

A maioria dos estádios fenológicos apresentaram alta porcentagem de contaminação por Fusarium spp. na espiga desde R1 até a pré-colheita, com exceção apenas para os híbridos RB9110 PRO2 e 2B633 PW da 2a safra, que obtiveram menores incidências do fungo nos estádios iniciais. O híbrido ADV 9275 PRO da $1^{\text {a }}$ safra possuiu variação na incidência fúngica ao longo dos estádios fenológicos, no R1 iniciou com 25\% e aumentou para 100\% em R3, reduzindo para $75 \%$ no estádio R4 e voltando a se elevar para 100\% no R6 e na pré-colheita. Todavia, o híbrido SEMPRE 20A30 da 1ª safra iniciou com média de $75 \%$ no R1 e, a partir do estádio R3, permaneceu com 100\% de incidência até a pré-colheita. Enquanto os híbridos RB9110 PRO2 e 2B633 PW da $2^{\mathrm{a}}$ safra demonstraram maior resistência ao fungo durante o desenvolvimento da cultura, apresentando as menores médias, sendo de 55,0 e 65,0\%, respectivamente. A maior incidência do fungo na espiga foi no híbrido $2 \mathrm{~A} 401 \mathrm{PW}$ da $2^{\mathrm{a}}$ safra, nesse caso, a média foi de $100 \%$ em todos os estádios fenológicos. Entre as safras analisadas, a maior incidência de Fusarium spp. na espiga foi registrada na $1^{\mathrm{a}}$ safra com média de $87,5 \%$, contra $78,75 \%$ na $2^{\mathrm{a}}$ safra. 
Os híbridos que apresentaram maior incidência de Fusarium spp. na espiga possuem a tecnologia PW (Powercore), usadas nos híbridos 2A401 PW e 2B512 PW, cultivadas na $2^{\mathrm{a}}$ safra, e a tecnologia Agrisure Viptera (VIP 3) utilizado no híbrido SEMPRE 20A30 semeada na $1^{\mathrm{a}}$ safra. Estas tecnologias possuem resistência as principais lagartas que atacam a cultura do milho, além de precocidade e alto potencial produtivo. Assim, estas características em comum podem ter proporcionado a semelhança dos resultados, mesmo entre os híbridos com materiais genéticos diferentes e produzidos em épocas distintas, obtendo alta incidência desde o início do desenvolvimento da espiga.

Outras pesquisas apresentaram incidência de Fusarium spp. nos grãos inferiores ao que foi observado neste estudo. Munhoz et al. (2015) realizaram um estudo com seis linhagens tropicais de milhos (três pré-classificadas como resistentes e outras três pré-classificadas como suscetíveis à $F$. verticillioides) submetidas à inoculação do patógeno após o início do florescimento da cultura e constataram uma variação média de incidência do fungo no grão entre 13,7 e 39,3\% na $1^{\text {a }}$ safra e de 4,2 e $22,7 \%$ na $2^{a}$ safra. Além disso, apenas duas linhagens, pré-classificadas como resistentes, apresentaram espigas sem podridão, contudo, somente uma entre essas duas apresentou resistência a produção de fumonisinas. Assim, grãos considerados assintomáticos a podridão rosada da espiga, não garantem a ausência de contaminação por fumonisinas produzidas pelo $F$. verticillioides.

Mendes et al. (2011) avaliando a qualidade sanitária de grãos de milho por meio da severidade do fungo Fusarium verticillioides, oriundos de diferentes híbridos comerciais, com e sem a inoculação artificial a campo no estádio fenológico R1, comprovaram variação média de severidade do patógeno entre 32,00 e 47,20\% para os grãos com inoculação e de 26,0 e 38,40\% para os grãos sem inoculação na primeira safra. Na segunda safra a porcentagem foi na ordem de 41,80 e 57,60\% e de 38,0 e $51,80 \%$ para grãos com e sem inoculação, respectivamente.

Tabela 4. Dados médios observados de incidência (\%) de Fusarium spp. na espiga em função do estádio fenológico, em diferentes híbridos e épocas de plantio. Em que: R1 (embonecamento), R3 (grão leitoso), R4 (grão pastoso), R6 (maturação fisiológica) e pré-colheita.

\begin{tabular}{|c|c|c|c|c|c|}
\hline \multicolumn{6}{|c|}{ Incidência (\%) de Fusarium spp. na $1^{\text {a }}$ Safra } \\
\hline Estádios & \multicolumn{2}{|c|}{ SEMPRE 20A30 } & \multicolumn{2}{|c|}{ ADV 9275 PRO } & Média geral \\
\hline R1 & \multicolumn{2}{|c|}{75,0} & \multicolumn{2}{|c|}{25,0} & 50,0 \\
\hline R3 & \multicolumn{2}{|c|}{100,0} & \multicolumn{2}{|c|}{100,0} & 100,0 \\
\hline $\mathrm{R} 4$ & \multicolumn{2}{|c|}{100,0} & \multicolumn{2}{|c|}{75,0} & 87,50 \\
\hline R6 & \multicolumn{2}{|c|}{100,0} & \multicolumn{2}{|c|}{100,0} & 100,0 \\
\hline Pré-Colheita & \multicolumn{2}{|c|}{100,0} & \multicolumn{2}{|c|}{100,0} & 100,0 \\
\hline Média geral & \multicolumn{2}{|c|}{95,0} & \multicolumn{2}{|c|}{80,0} & 87,5 \\
\hline \multicolumn{6}{|c|}{ Incidência (\%) de Fusarium spp. na $2^{\mathrm{a}}$ Safra } \\
\hline Estádios & RB9110 PRO2 & 2A401 PW & 2B512 PW & 2B633 PW & Média geral \\
\hline R1 & 25,0 & 100,0 & 75,0 & 25,0 & 56,25 \\
\hline R3 & 25,0 & 100,0 & 100,0 & 50,0 & 68,75 \\
\hline $\mathrm{R} 4$ & 50,0 & 100,0 & 100,0 & 75,0 & 81,25 \\
\hline R6 & 75,0 & 100,0 & 100,0 & 75,0 & 87,50 \\
\hline Pré-Colheita & 100,0 & 100,0 & 100,0 & 100,0 & 100,0 \\
\hline Média geral & 55,0 & 100,0 & 95,0 & 65,0 & 78,75 \\
\hline
\end{tabular}

A incidência fúngica ocorrida na planta como um todo, mas principalmente na espiga, é o fator mais crítico observado, pois atrela-se a isso a contaminação dos grãos até sua colheita, com possibilidades de desenvolvimento de micotoxinas. De modo geral identificou-se períodos de redução do inóculo ou que apresentavam incidência menor que $50 \%$ em R3 e R4 na $1^{\mathrm{a}}$ safra nas folhas e no pendão. $\mathrm{Na} 2^{\mathrm{a}}$ safra a incidência do fungo na folha permaneceu inferior a $50 \%$ em R3 e no pendão esteve acima de $50 \%$ desde o VT. Há diferenças peculiares entre $1^{\mathrm{a}}$ e $2^{\mathrm{a}}$ safras dependente do clima, assim como no tipo de híbrido. O material 
que apresentou menor incidência média na espiga até R6 foi o RB9110 PRO2 que possui como principal característica ótima sanidade do colmo e das raízes (Tabela 1), o que pode estar atrelado a forma como o Fusarium coloniza a planta.

\section{Considerações Finais}

Pode-se concluir que as condições climáticas, temperatura em torno de $22-29{ }^{\circ} \mathrm{C}$ e umidade relativa do ar de $63-98 \%$, encontradas no estado de Mato Grosso para os períodos entre $1^{\mathrm{o}}$ de dezembro a 06 de março $\left(1^{\mathrm{a}}\right.$ safra) e 03 de março a 07 de junho ( $2^{\mathrm{a}}$ safra) são favoráveis ao desenvolvimento de Fusarium spp.

Observa-se uma tendência de aumento da contaminação por Fusarium spp. em todas as partes da planta com o desenvolvimento da cultura e, ainda, os estádios fenológicos finais do milho, maturação fisiológica (R6) e pré-colheita, apresentam as maiores incidências fúngicas, independente do híbrido e época de plantio.

Os híbridos SEMPRE 20A30 semeado na $1^{\mathrm{a}}$ safra e 2A401 PW e $2 \mathrm{~B} 512 \mathrm{PW}$ cultivados na $2^{\mathrm{a}}$ safra possuem maior incidência por Fusarium spp., com média de 95, 100 e 95\%, respectivamente, enquanto o material RB9110 PRO2 tem maior resistência ao fungo.

$\mathrm{Na} 1^{\mathrm{a}}$ safra os híbridos apresentam maior incidência de Fusarium spp. na espiga, ao passo que na $2^{\mathrm{a}}$ safra a incidência foi maior na folha e pendão.

Com isso, é evidente a importância da identificação dos momentos mais críticos em que ocorre a infecção por Fusarium spp. em grãos de milho. Estudos futuros deverão correlacionar tecnologia e momento de aplicação de fungicidas visando efetividade de controle deste fitopatógeno em grãos de milho, bem como avaliação dos níveis de micotoxinas, para obtenção de grãos sadios que atendam a demanda de segurança alimentar da população.

\section{Referências}

Alfenas, A. C. \& Mafia, R. G. (2007). Métodos em fitopatologia. Ed. UFV, 382p.

Bento, L.F., Caneppele, M. A. B., Albuquerque, M. C. F., Kobayasti, L, Caneppele, C. \& Andrade, P. J. (2012). Ocorrência de fungos e aflatoxinas em grãos de milho. Revista Instituto Adolfo Lutz, 71(1):44-9.

Brasil (2009). Ministério da Agricultura e da Reforma Agrária. Regras para análise de sementes. Brasília, 397 p.

Brevant (2021). 2A401PW. https://www.brevant.com.br/produtos/milho/2a401pw.html

CONAB. Companhia Nacional de abastecimento (2021). Boletim de grãos-setembro de 2021. https://www.conab.gov.br/info-agro/safras/graos/boletim-dasafra-de-graos

Costa, R. V., Simon, J., Cota, L. V., Silva, D. D., Almeida, R. E. M., Lanza, F. E., Lago, B. C., Pereira, A. A., Campos, L. J. M. \& Figueiredo, J. E. F. (2019). Yield losses in off-season corn crop due to stalk rot disease. Pesquisa Agropecuária Brasileira, 54(00283). https://doi.org/10.1590/S16783921.pab2019.v54.00283.

Fancelli, A. L. \& Dourado Neto, D. (2000). Produção de milho. Guaíba: Agropecuária, 360p.

Forseed (2021a). 2B512PW. https://www.forseedsementes.com.br/portfolio/produtos/2b512pw-3/

Forseed (2021b). 2B633PW. https://www.forseedsementes.com.br/portfolio/produtos/2b633pw/

Gabriel, L. C., Pereira, C. B., Bavia, G. P., Coan, M., Donel, A. A., Tessmann, D. J. \& Scapim, C. A. (2018). Avaliação da resistência de genótipos de milho pipoca ao acúmulo de fumonisinas e à podridão de Fusarium da espiga. Summa Phytopathol, 44(3), 286-288. https://doi.org/10.1590/0100-5405/179360

Gaige, A. R., Todd, T. \& Stack, J. P. (2020). Interspecific Competition for Colonization of Maize Plants Between Fusarium proliferatum and Fusarium verticillioides. Plant Disease, 104(8), 2102-2110. https://doi.org/10.1094/PDIS-09-19-1964-RE

Instituo Nacional de Meteorologia (INMET). Banco de dados meteorológicos para ensino e pesquisa. http://www.inmet.gov.br/portal/index.php?r=bdmep/bdmep. 
Sempre (2021). SEMPRE 20A30. https://www.sempre.agr.br/produto/milho

Juliatti, F. C., Zuza, J. L. M. F., Souza, P. P. \& Polizel, A. C. (2007). Efeito do Genótipo de Milho e da Aplicação Foliar de Fungicidas na Incidência de Grãos Ardidos. Bioscience Journal, 23(2), 34-41. http://www.seer.ufu.br/index.php/biosciencejournal/article/view/6509

Kimati, H., Amorim, L. \& Bergamin, A. F. Manual de Fitopatologia: princípios e conceitos. São Paulo, Ed Agronômica CERES, 3. v.1, p.919, 1995.

Köppen, W. \& Geiger, R. (1936). Classificação climática de Köppen-Geiger.

Kühn, I. E., Cotrim, M. F., Gava, R., Alvarez, R. C. F., Oliveira, J. T. \& Teodoro, P. E. (2020). Center pivot irrigation management in maize hybrids and the incidence of stalk rot. Revista Brasileira de Engenharia Agrícola e Ambiental, (24)12, 840-846. http://dx.doi.org/10.1590/1807-1929/agriambi.v24n12p840-846

KWS (2021). RB9110 - Versões PRO e PRO2. https://www.kws.com/br/pt/produtos/milho/portfolio-completo-milho/rb9110-pro-pro2-e-pro3/

Marcia, B. A. \& Lazzari, F. A. (1998). Monitoramento de fungos de milho em grão, grits e fubá. Ciência e Tecnologia de Alimentos, $18(4), 363$-367.

Marcondes, M. M. (2012). Incidência de podridão de colmo e grão ardidos em híbridos de milho sob diferentes densidades de plantas e épocas de colheita. Universidade Estadual do Centro-Oeste. Guarapuava - PR.

Mendes, M. C., Pinho, R. G. V., Machado, J. C., Albuquerque, C. J. B. \& Falquete, J. C. F. (2011). Qualidade sanitária de grãos de milho com e sem inoculação a campo dos fungos causadores de podridões de espigas. Ciência e Agrotecnologia, 35(5), 931-939. https://doi.org/10.1590/S1413-70542011000500010

Munhoz, A. T., Carvalho, R. V., Querales, P. J., Gonçalves, F. P. \& Camargo, L. E. A. (2015). Relação entre resistência de linhagens tropicais de milho à podridão de espiga e ao acúmulo de fumonisinas provocados por Fusarium verticillioides. Summa Phytopathologica, 41(2), 144-148. https://doi.org/10.1590/0100-5405/1962

Nirenberg, H. I. \& O'donnell, K. (1998). New Fusarium species and the combinations within the Gibbrella fujikoroi species complex. Mycologia, 90, 434-458.

Oliveira, I. J., Fontes, J. R. A., Barreto, J. F. \& Pinheiro, J. O. C. (2018). Recomendações técnicas para o cultivo de milho no Amazonas. Manaus: Embrapa Amazônia Ocidental, 28p. (Circular técnica 68).

Pereira, A. S., Shitsuka, D. M., Parreira, F. J., \& Shitsuka, R. (2018). Metodologia da pesquisa científica. [free e-book]. Santa Maria/RS. Ed. UAB/NTE/UFSM. 5.3)

Prestes, I. D., Rocha, L. O., Nuñez, K. V. M. \& Silva, N. C. C. (2019). Principais fungos e micotoxinas em grãos de milho e suas consequências. Scientia Agropecuária, 10(4), 559-570. http://dx.doi.org/10.17268/sci.agropecu.2019.04.13

Scheidt, B. T., Casa, R. T., Fiorentin, O. A., Martins, F. C., Kuhnem, P., Lima, A. \& Farias, M. (2019). Determination of the most susceptible phenological stage of rice panicles to infection by species of Fusarium graminearum. Summa Phytopathol, 45(3), 243-246. https://doi.org/10.1590/0100-5405/192513

Silva, J. S. (2008). Secagem e armazenagem de produtos agrícolas. In: Silva, J. S., Berbert, P. A., Afonso, A. D. L., Ruffato, S. Qualidade de grãos. pp. 63-105. 2th ed. Viçosa: Aprenda Fácil. 560p.

Silva, H. Fantin, G. M., Resende, I. C., Pinto, N. F. J. A. \& Carvalho, R. V. (2001). Manejo Integrado de Doenças na Cultura do Milho de Safrinha In: Seminário Nacional De Milho Safrinha. 2001, Londrina: Iapar. pp. 113-144.

Souza, A. P., Mota, L. L., Zamadei, T., Martim, C. C., Almeida, F. T. \& Paulino, J. (2013). Classificação climática e balanço hídrico climatológico no Estado de Mato Grosso. Nativa, 1(1), 34-43. https://doi.org/10.31413/nativa.v1i1.1334

Venceslau, D. D., Ruffato, S. \& Bonaldo, S. M. (2015). Qualidade sanitária de grãos de soja em função da época de colheita. Scientia Agraria Paranaensis,14(1), 25-32. 10.18188/1983-1471/sap.v14n1p25-32

Wilke, A. L., Bronson, C. R., Tomas, A., \& Munkvold, G. P. (2007). Seed transmission of Fusarium verticillioides in maize plants grown under three different temperature regimes. Plant Disease, 91, 1109-1115. 10.1094/ PDIS-91-9-1109 